\title{
CLINICOPATHOLOGICAL AND IMMUNOHISTOCHEMISTRY BASED DIAGNOSIS OF A RARE VIRILIZING ADRENOCORTICAL ADENOMA IN A 13 MONTH OLD MALE CHILD: A CASE REPORT
}

\author{
M. Ramani, Akhila Puskuru, O. H. Radhika Krishna, K. Geetha, A. Narendra Kumar
}

\begin{abstract}
1. Professor, Department of Pathology, Niloufer Hospital, Institute of Child Health.
2. Post Graduate, Department of Pathology, Niloufer Hospital, Institute of Child Health.

3. Assistant Professor, Department of Pathology, Niloufer Hospital, Institute of Child Health.

4. Assistant Professor, Department of Pathology, Niloufer Hospital, Institute of Child Health.

5. Professor, Department of Pediatric Surgery, Niloufer Hospital, Institute of Child Health.
\end{abstract}

\section{CORRESPONDING AUTHOR}

Dr. M. Ramani

Professor of Pathology

Niloufer Hospital,

E-mail: drmramani@sify.com

Ph: 00919849134064

\begin{abstract}
ABSRACT: Adrenocortical tumors are rare in childhood and adolescence. They account for $0.2 \%$ of pediatric tumors. Adrenal tumors that exclusively secrete androgens are rare. We here report a case of 13 month old male child with androgen secreting right adrenal gland tumor. The child presented with frontal baldness, acne, pubic hair and enlarged penis. This case is presented because of its rarity.
\end{abstract}

KEY WORDS: Adrenocortical adenoma, virilizing, 13 month old male child.

INTRODUCTION: Adrenocortical tumors are rare in childhood and adolescence (1). They account for $0.2 \%$ of pediatric tumors. Childhood adrenocortical tumors occur predominantly in females. If they produce hormones, it is called a functioning tumor. Non-functioning tumors, most common type in adults, comprise approximately $10 \%$ of pediatric age group. Virilizing tumors are the most common type of functioning tumors. Adrenal adenomas are benign tumors of the adrenal gland. The histological features overlap with an adrenocortical carcinoma and need to be evaluated carefully as complete excision is curative in an adenoma unlike in carcinoma which may need adjuvant therapy and follow-up.

CASE HISTORY: A 13-month-old male child presented with three months history of excessive crying and abdominal pain. Physical examination revealed short span of hair on forehead, acne, pubic hair and enlarged penis. Systemic examination of CVS, CNS, Respiratory systems were normal. Abdomen was distended and tenderness noted in the right hypochondriac and lumbar regions.

Lab investigations revealed elevated testosterone levels, urine catecholamines, VMA spot test was negative and cortisol and aldosterone levels were normal. Ultrasonography showed right suprarenal mass .CT abdomen showed well delineated mildly enhancing lesion measuring $60.1 \times 48.0 \times 47.5 \mathrm{~mm}$ located in right adrenal gland and mild indentation on right pole of kidney. Left adrenal gland was normal. Color Doppler and 2D echo showed mild left ventricular hypertrophy. Clinical diagnosis of androgen secreting right adrenal gland tumor was made. (Figure 1).

Right adrenalectomy was done and we received a globular soft tissue mass weighing $30 \mathrm{~g}$ and measuring $4.5 \times 3.5 \times 3 \mathrm{~cm}$. Cut section was grey-tan, homogenous and encapsulated. 
Microscopy revealed tumor tissue surrounded by fibrous capsule. Tumor was arranged in solid sheets and trabeculae composed of polygonal cells with moderate amount of eosinophilic cytoplasm and round to oval hyperchromatic nuclei. Focal multinucleation is seen. Fibrosis, necrosis, vascular and capsular invasion were absent. (Figure 2).

IHC: IHC of the tumor showed strong positivity for calretinin and inhibin suggesting adrenocortical origin and strong positivity for cytokeratin, weak positivity of vimentin and low Ki 67 labeling index suggests an adenoma (Figure 3).

Based on the size, weight, gross and microscopic features, Weiss criteria and IHC, a final diagnosis of adrenocortical adenoma with virilization was made. Post operatively testosterone levels returned to normal. Patient is on regular follow-up with 6 monthly hormonal level assessment \& USG abdomen.

DISCUSSION: Adrenocortical tumors are rare pediatric neoplasms (1). Adrenal adenomas are benign tumors of adrenal gland. They occur predominantly in females. Functional tumors secrete several hormones and thus present with signs and symptoms of multiple syndromes (mixed forms). Virilization is frequent in children and indicates $70 \%$ chance of malignancy (2).

Grossly, if the size of the tumor is $<5 \mathrm{~cm}$, weight $<50 \mathrm{~g}$ and if cut section is homogenous grey tan without areas of necrosis and hemorrhage, then the tumor is considered to be benign. But malignancy and metastasis can occur in tumors weighing $<50 \mathrm{~g}$. Microscopically distinction between benign and malignant neoplasms is difficult. Weiss criteria (3) is employed to distinguish benign from malignant tumors.

\section{WEISS CRITERIA INCLUDE:}

1. High nuclear grade

2. Mitotic figures $>5 / 50 \mathrm{hpf}$

3. Atypical mitotic figures

4. Eosinophilic cytoplasm $>75 \%$ tumor cells

5. Diffuse architecture $>1 / 3$ of tumor

6. Necrosis

7. Venous invasion

8. Sinusoidal invasion

9. Capsular invasion

The score of three or more suggests malignancy.

\section{MODIFIED WEISS CRITERIA (4) INCLUDE:}

$2 \mathrm{x}$ mitotic rate score $+2 \mathrm{x}$ clear cytoplasm score + abnormal mitoses + necrosis + capsular invasion

The score of 3 or more suggests malignancy.

In pediatric population, if the tumor size $>10 \mathrm{~cm}$, weight $>400 \mathrm{~g}$ and mitoses $>15 / 20 \mathrm{HPF}$ it is considered as malignant ${ }^{(5)}$.

In the present case, the weight of the tumor was $30 \mathrm{~g}$, size $4.5 \mathrm{~cm}$, with homogenous cut section and according to Weiss criteria the score was 2 . So the tumor was diagnosed as benign. IHC of the tumor showed strong positivity for calretinin and inhibin suggesting adrenocortical origin and strong positivity for cytokeratin supports the diagnosis of adenoma, weak positivity 
of vimentin and low Ki 67 labeling index ruled out the possibility of adrenocortical carcinoma (6, 7).

Variants of adrenocortical adenoma include black adenoma, myelolipoma, corticomedullary mixed tumor, oncocytoma, lipoadenoma and myxoid variants.

CONCLUSION: Adrenocortical tumors are extremely rare neoplasms and it is essential to differentiate adenoma from carcinoma. Surgery is the single most important procedure in successful treatment of adrenocortical adenomas. Prognosis is excellent for patients with adenoma histology. Virilizing and feminizing adrenocortical tumors are viewed with concern for their malignant potential. This case is presented in view of highlighting a rare case of pediatric virilizing adrenocortical adenoma.

\section{REFERENCES:}

1. Michalkiewicz E, Sandrini R, Figueiredo B, Miranda EC, Caran E, Oliveira-Filho AG, et al. Clinical and outcome characteristics of children with adrenocortical tumors: a report from the International Pediatric Adrenocortical Tumor Registry. J Clin Oncol. 2004 Mar $1 ; 22(5): 838-45$.

2. Latronico AC, Pinto EM, Domenice S, Fragoso MC, Martin RM, Zerbini MC, et al. An inherited mutation outside the highly DNA-binding domain of the P53 tumor suppressor protein in children and adults with sporadic adrenocortical tumors. J Clin Endocrinol Metab 2001; 86: 4970-3.

3. Weiss LM. Comparative histologic study of 43 metastasizing and non metastasizing adrenocortical tumors. Am J Surg Pathol. 1984 Mar; 8(3): 163-9.

4. Aubert S, Wacrenier A, Leroy X, Devos P, Carnaille B, Proye C, et al. Weiss system revisited: a clinicopathologic and immunohistochemical study of 49 adrenocortical tumors. Am J Surg Pathol. 2002 Dec; 26(12):1612-9.

5. Lau SK, Weiss LM. The Weiss system for evaluating adrenocortical neoplasms: 25 years later. Hum Pathol. 2009 Jun; 40(6):757-68.

6. Richard J. Cote, Carlos Cordon-Cardo, Victor E. Reuter, Paul Peter Rosen. Immunopathology of adrenal and renal cortical tumors. Coordinated change in antigen expression is associated with neoplastic conversion in the adrenal cortex. Am J pathol. 1990 May; 136(5): 1077-84.

7. Terzolo M, Boccuzzi A, Bovio S et al. Immunohistochemical assessment of Ki 67 in differential diagnosis of adrenocortical tumors. Urology. 2001 Jan; 57(1):176-82. 


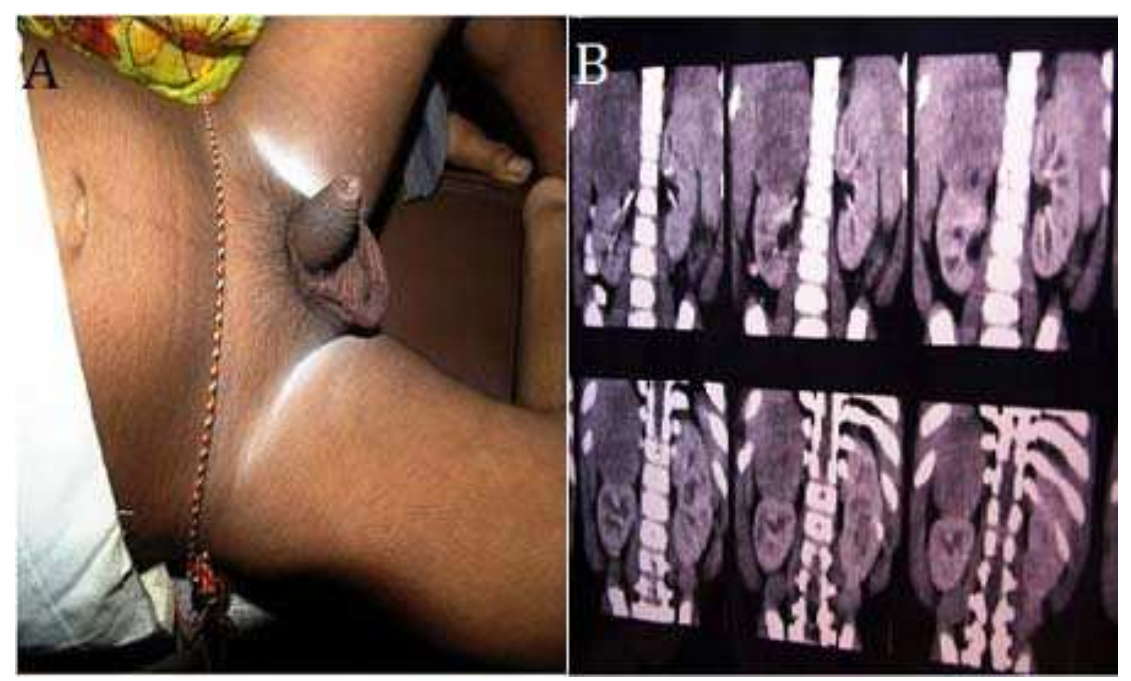

Figure 1: (a) Clinical features of pubic hair and enlarged penis (b) CT showing well delineated mass in right adrenal gland and indentation on upper pole of right kidney.

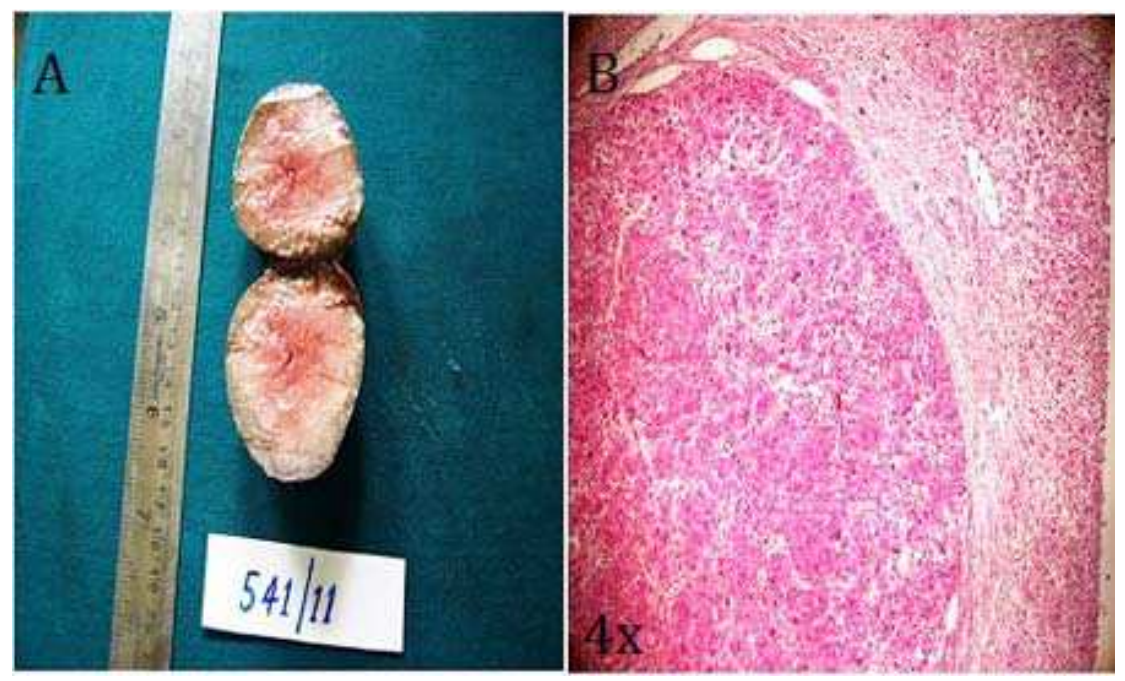

Figure 2: (a) Grossly tumor is homogenous, grey-tan and encapsulated. (b)Tumor surrounded by fibrous capsule. 


\section{CASE REPORT}

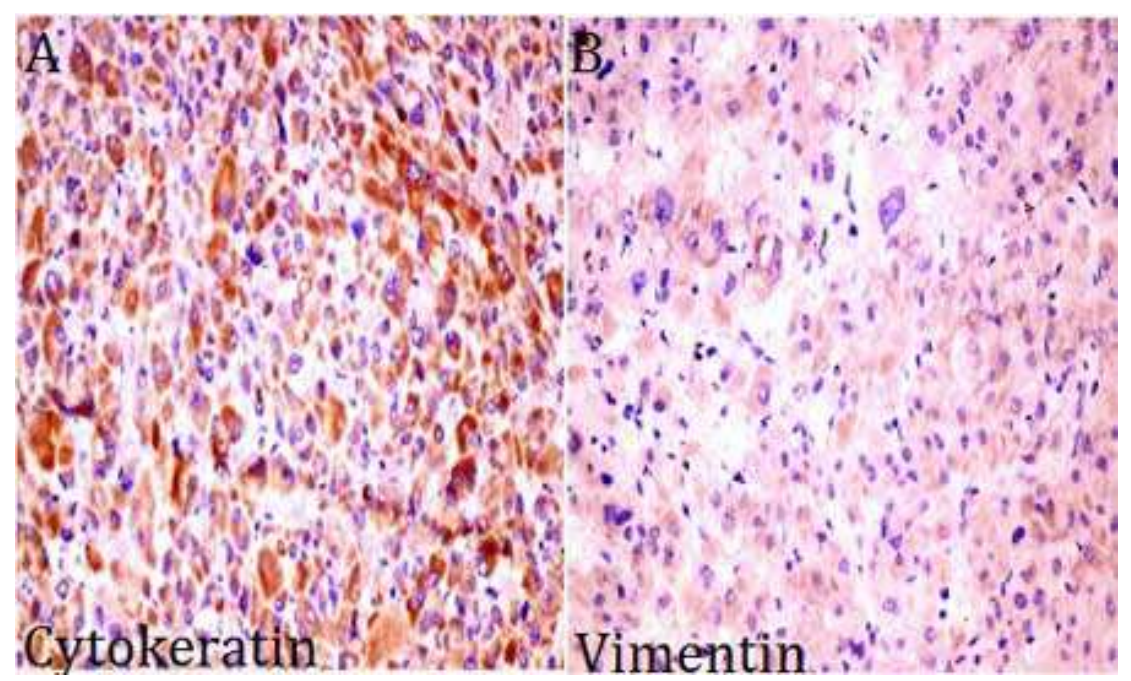

Figure 3: (a) Strong positivity of cytokeratin and (b) Weak positivity of vimentin. 